\title{
Feasibility of Nanofiltration process in dual stage in desalination of the seawater
}

\author{
F. El Azhar ${ }^{1 *}$, N. El Harrak ${ }^{1}$, M. El Azhar ${ }^{1}$, M.Hafsi $^{2}$, A.Elmidaoui $^{1}$ \\ ${ }^{1}$ Laboratory of Separation Processes, Department of Chemistry, Faculty of Science University Ibn Tofail, B.P \\ 1246, Kenitra 14000 - Morocco \\ ${ }^{2}$ Office National de l'Eau Potable (ONEP), Rabat, Morocco.
}

\begin{abstract}
The main objective of this paper is to predict the performances of NF membranes for seawater desalination utilizing a two. ROSA software was used in this study to verify the applicability of the NF in dual stage desalination process. Similarly to dual stage NF desalination process, an NF membrane was used in the first stage and $B W$ membrane in the second stage. The first stage includes a nanofiltration membrane, but the second includes a nanofiltration or reverse osmosis $(B W)$ membranes in order to produce potable water (TDS less than $1000 \mathrm{mg} / \mathrm{l}$ ). The effect of membranes type and seawater salinity is examined to achieve our objective. The results of energy requirements of $N F-N F$ and $N F-B W$ were eventually compared to single stage RO desalination in order to estimate the effectiveness of process.
\end{abstract}

Keywords: Nanofiltration, Reverse osmosis, Desalination, Rosa software, Dual stage.

\section{Introduction}

Increase of worldwide shortage of fresh water resources and recent reduction in cost of desalination technologies has enhanced the interest in potable water production from saline or brackish waters. Currently, two different processes are mainly used for seawater desalination, thermal evaporation by distillation and membrane technologies. The latter represents about $56.5 \%$ of the world separation systems (Silva et al. 2011). In such processes, the RO is the widely used method for seawater desalination. $90 \%$ of desalination plants commissioned in 2007-2008 is based on RO technology, but He still requires an intensive pre-treatment to prevent membrane fouling, and higher energy consumption.

However, in order to reduce or even overcome these limits, recently, several studies have been showed that de NF process can be an alternative to reverse osmosis for seawater desalination (Diem et al. 2006).This will enhance the production of desalted water and reduces its production cost.

NF membrane was found to be successful in removal of divalent ions (exceeded 98\%), turbidity, significant removal of residual bacteria, scale forming hardness ions, lowering of the seawater TDS (Wang et al. 2000). Therefore, the main advantage of NF membranes is the lower energy consumption compared to RO membranes (Noronha et al. 2002).

The main objective of this paper is to predict the performances of NF in dual stage in seawater desalination using ROSA design software. This alternative consist to treating the permeat from NF membrane the first stage with a second NF and BW stage in order to produce produce finished water with salinity levels according to the OMS guidelines of drinking water, and to reduce energy consumption to as low as possible while producing potable water at an acceptable recovery rate.

For this, various combinations, salinities and many configurations are examined to achieve our objective. Results from using different types of NF and BWRO membranes were eventually compared in terms of quality, energy and cost with a single RO membrane seawater.

\section{Methods And Materials}

\subsection{Rosa Software}

ROSA (Nissan et al. 2005), for instance, is the software developed by Dow chemical company that incorporates a model for RO/ NF process. The software has been used with success for the analysis of the performance of membranes, energy requirements and cost for desalination (Nissan et al. 2005; Karameldin et al. 2005).

Since there is a scarcity of backup simulation programs, which allow operating conditions to be estimated, the essential design parameters are often determined using pilot plants in a time consuming and costintensive manner. Moreover, a great deal of uncertainty is involved in designing industrial membrane processes if testing on a pilot scale is not conducted. In most cases, optimization during the pilot phase is mostly based on the empirical method, involving the special know-how of the user. This also results in a lengthy period of process development. 
The software allows virtual creation of the basic RO/NF design with the choice of feed water composition, feed water flow rate, feed water pressure, temperature and $\mathrm{pH}$. Then, a configuration of the number of membranes, pressure vessels, type of membrane, feed and booster pumps is determined. The software has been used in many research papers (Chen et al. 2005; Karameldin et al. 2005; Moreno et al.2004; Nissan et al.2005).

In this way several calculation runs could be done by changing various input conditions and determining the performance.

\subsection{Seawater composition}

The composition of seawater used in this study is described in Table 1. Initially, the concentration of seawater is $35,000 \mathrm{ppm}$; for simplicity the concentrations from $37,000 \mathrm{ppm}$ to $43,000 \mathrm{ppm}$ were estimated by equally increasing the concentrations of sodium and chlorides ions only.

Table 1: seawater composition

\begin{tabular}{|c|c|}
\hline Température ${ }^{\circ} \mathrm{C}$ & 23 \\
\hline Conductivité $\mu \mathrm{S} / \mathrm{cm}$ & 42.800 \\
\hline $\mathrm{pH}$ & 8.08 \\
\hline Turbidité NTU & 2.4 \\
\hline $\mathrm{TDS} \mathrm{mg/l}$ & 36.380 \\
\hline $\mathrm{Ca}^{2+} \mathrm{ppm}$ & 480 \\
\hline $\mathrm{Mg}^{2+} \mathrm{ppm}$ & 1488 \\
\hline $\mathrm{HCO}_{3}{ }^{-} \mathrm{ppm}$ & 146 \\
\hline $\mathrm{Cl}^{-} \mathrm{ppm}$ & 21300 \\
\hline $\mathrm{Na}^{+} \mathrm{ppm}$ & 12080 \\
\hline $\mathrm{SO}_{4}{ }^{2-} \mathrm{ppm}$ & 2777 \\
\hline
\end{tabular}

\subsection{Membranes and configurations tested}

Table 2 gives the characteristics of the tested membranes.

Table 2: Characteristics of the tested membranes

\begin{tabular}{|c|c|c|c|c|c|c|}
\hline Membrane & $\begin{array}{c}\text { Surface } \\
\left(\mathrm{m}^{2}\right)\end{array}$ & $\begin{array}{c}\mathrm{P} \max \\
(\mathrm{bar})\end{array}$ & $\mathrm{pH}$ & $\begin{array}{c}\text { Max temp } \\
\left({ }^{\circ} \mathrm{C}\right)\end{array}$ & Materials & $\begin{array}{c}{\left[\mathrm{Cl}_{2}\right] \text { tolerance }} \\
\mathrm{ppm}\end{array}$ \\
\hline BW30-365 & 7.6 & 41 & 2 à 11 & 45 & polyamide & 0.1 \\
\hline BW30-400 & 7.6 & 41 & 3 à 10 & 45 & polyamide & 0.1 \\
\hline NF90-400 & 7.6 & 41 & 3 à 10 & 45 & polyamide & 0.1 \\
\hline
\end{tabular}

Two combinations were investigated in the current study such as, NF-NF, NF-BW for each membrane type five tests was conducted.

The figures 1 and 2 give the tested configurations: dual stage and dual stage supplied Bach.

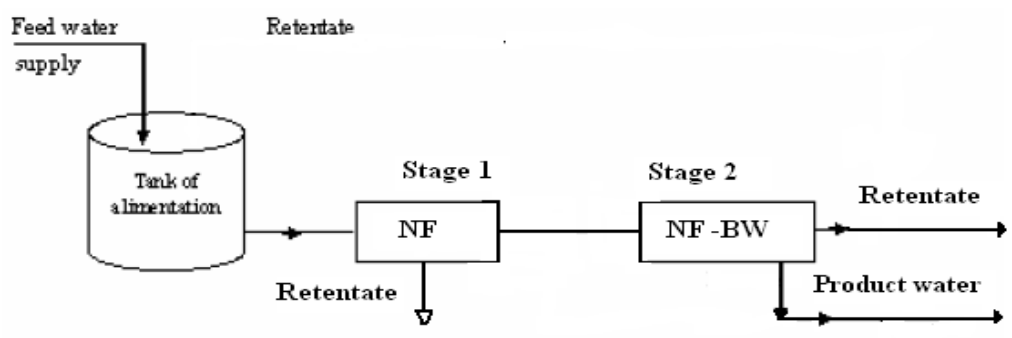

Fig 1: dual stage

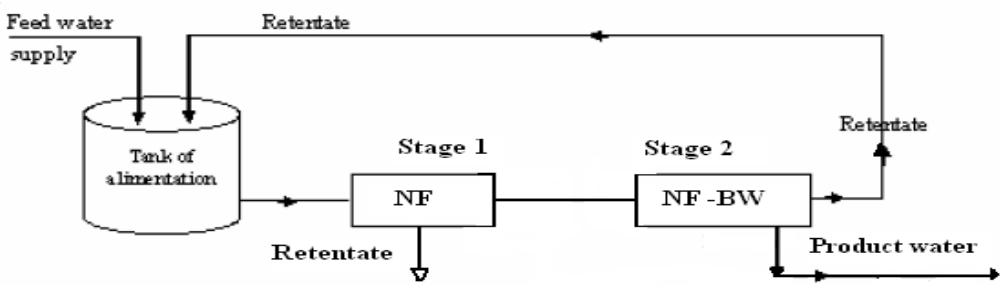

Fig 2: dual stage supplied Bach 


\subsection{Input conditions}

Table 3 gives the input conditions.

Table 3: inputs conditions.

\begin{tabular}{|l|c|c|}
\hline INPUT CONDITION & Etage1 & Etage 2 \\
\hline Nombre de tube de pression & 1 & 1 \\
\hline Nombre de membrane / tube de pression & 6 & 5 \\
\hline $\mathrm{pH}$ & 8,1 & ------ \\
\hline Température & $25^{\circ} \mathrm{C}$ & ------ \\
\hline Débit d'alimentation & $170 \mathrm{~m}^{3} / \mathrm{j}$ & - \\
\hline Feed salinity $(\mathrm{mg} / \mathrm{l})$ & $35000,37000,39000$, & --- \\
\hline Membrane & 41000,43000 & NF90-400, BW30-400, \\
& NF90-400 & BW 30-365 \\
\hline
\end{tabular}

In our case, the output parameters include: TDS permeate, pressure, and energy requirement.

\section{Results And Discussion}

The simulation by Rosa software was carried out in two configurations to predict the performances of NF process in the dual stage for seawater desalination. The operations of simulation were conduced for various initial salinities of the feed water 35000, 37000, 39000, 41000 and 43000 ppm, and various combinations NFNF and NF-BW.

In the first, the adopted configuration is dual stage, the permeate of one stage is pressurized in second stage to produce a potable water, will the first and second retentate is rejected

\subsection{Configuration 1:}

Figure 3 gives the variation of total recovery as a function of the initial feed salinity for the two tested combinations. According to figure 3, the total recovery is the same value for each salinity and each combination. Although the total recovery decreased with increased feed salinity, these results can be attributing to the increase in osmotic pressure in feed salinity.

The recovery rate in stage 1 and 2 is shown in figure 4; also the recovery rate decreased with increased feed salinity, de plus the recovery rate in stage 1 is higher than the second stage. This was mainly due to difference pressure applied in the two pass. The variation of the applied pressure in two stages as a function of the feed salinity for the two tested combinations is given in figure 5 .

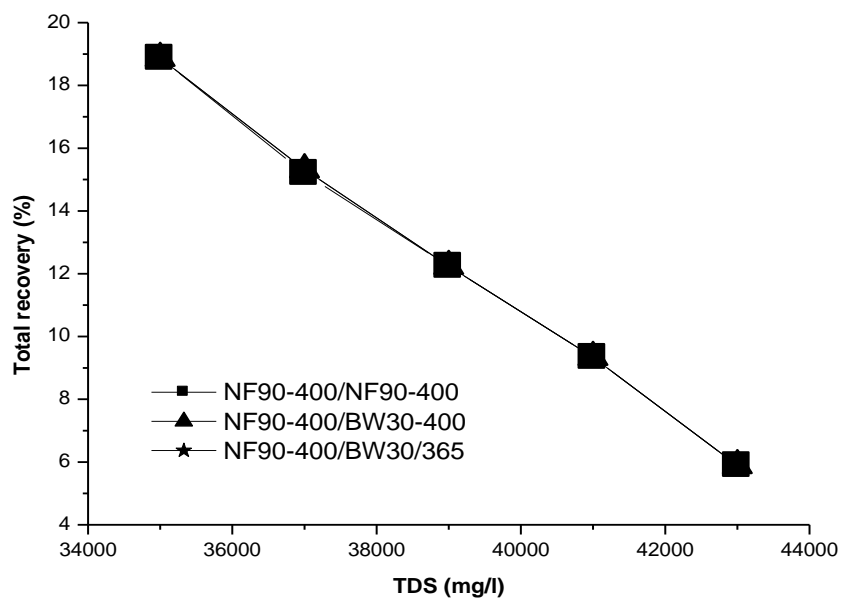

Figure 3: Variation of total recovery as a function of the initial feed salinity for the tested combinations 


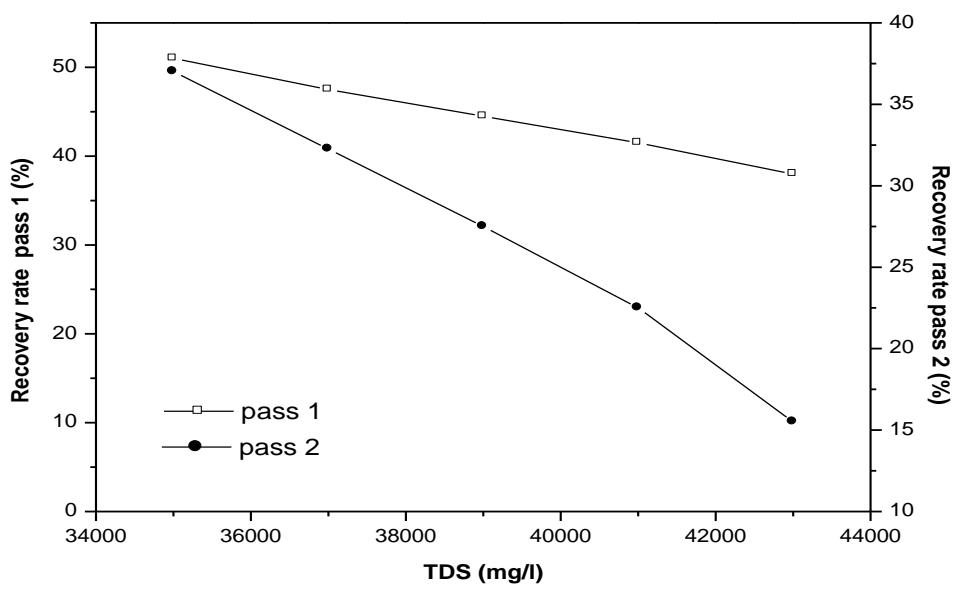

Figure 4: Variation of recovery rate in stage 1 and 2 as a function of the initial feed salinity for the tested combinations.

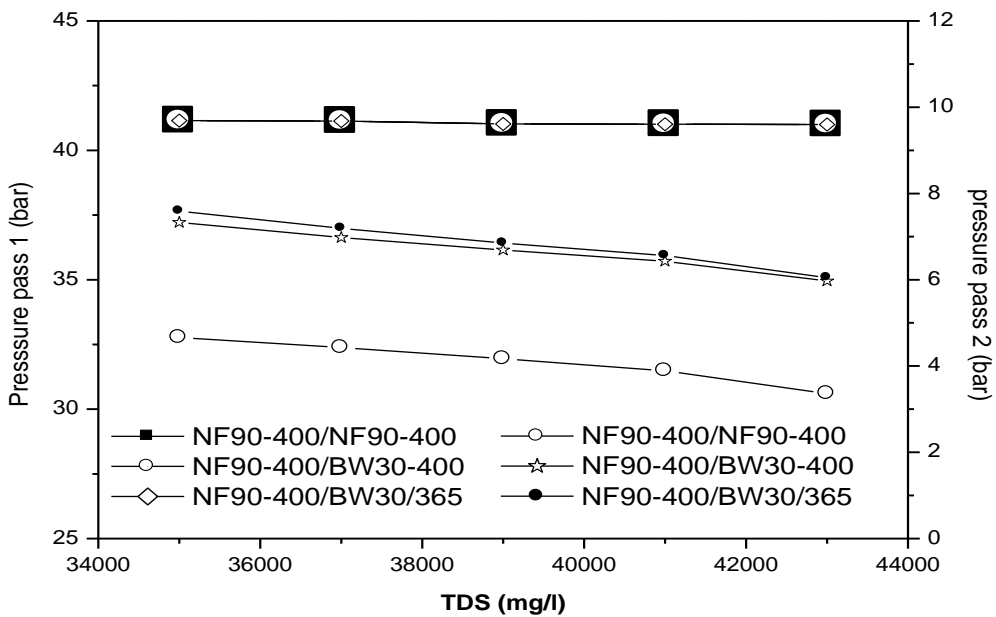

Figure 5: Variation of applied pressure in stage 1 and 2 as a function of the initial feed salinity for the tested combinations.

According to figure 5, the analysis for the results showed that, the applied pressure is higher in first stage than in the second stage. In first stage the applied pressure is the same for each salinity, this was because the using one type of membrane NF90 and the identical feed flow.

But in the second stage the applied pressure varied as a function of the each salinity and combination. The applied pressure for BW membrane is higher than NF membrane. It is evident because the difference of the used membranes composition and the feed flow in second stage.

As predicted by Rosa software, the composition of the permeate in term the TDS is shown in figure 6 for each combination and salinity tested. The lower permeate TDS was obtained for BW membrane, but the higher rejection was obtained with this, the permeate TDS increased with increased feed salinity. 


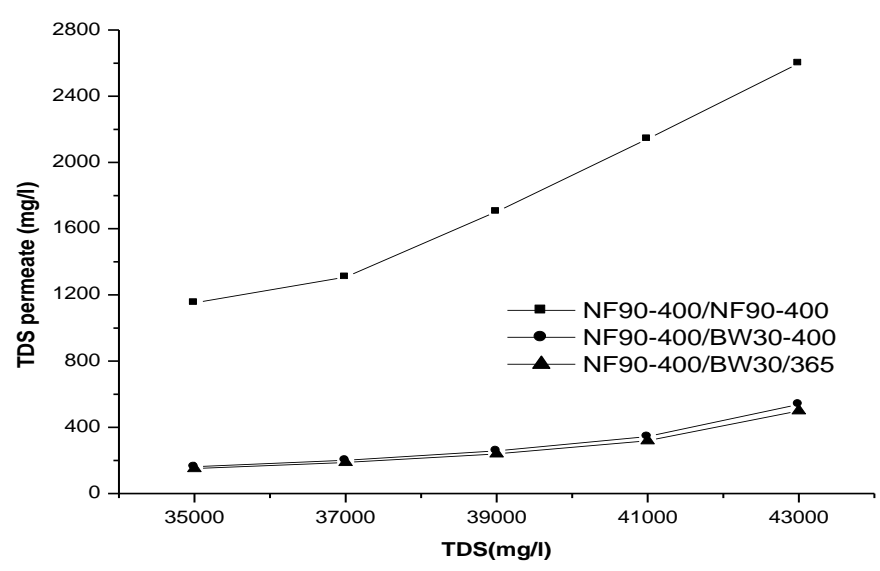

Figure 6: Variation of permeate TDS as a function of the initial feed salinity for the tested combinations.

The energy consumption and water salinity for the different combination is illustrated in Figure 7. It shows that the energy consumption increase with increasing feed solution concentration. This is valid for either $\mathrm{RO}$ or NF treatment processes because this energy is proportional to the quantity of salt to eliminate. The energy demand was the lowest for the NF-NF combination.

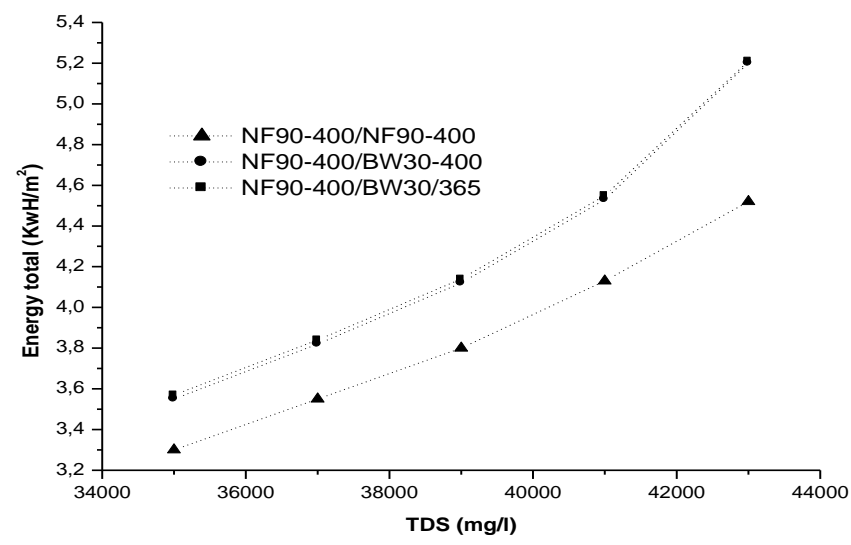

Figure 7: Variation of total energy consummation as a function of the initial feed salinity for the tested combinations.

After analysis of the results, it is clear that the configuration dual stage give a permeate with a salinity of less than $1000 \mathrm{ppm}$ especially with the combination NF-BW, and higher than $1000 \mathrm{ppm}$ with NF-NF. Although it can be seen that the total recovery is very low, it is equal to $5.39 \%$ for TDS of $43,000 \mathrm{mg} / 1$ for each combination.

In order to increase the total recovery and have a better quality with NF-NF, the operations of simulation by Rosa were conducted using configuration dual stage supplied batch. The first retantate is rejected, while the second retentate is recalculated to the tank of alimentation.

\subsection{Configuration 2:}

The figures $8,9,10$ give the variation of total recovery, permeate TDS, and energy as a function of the initial feed salinity for the tested combinations. 


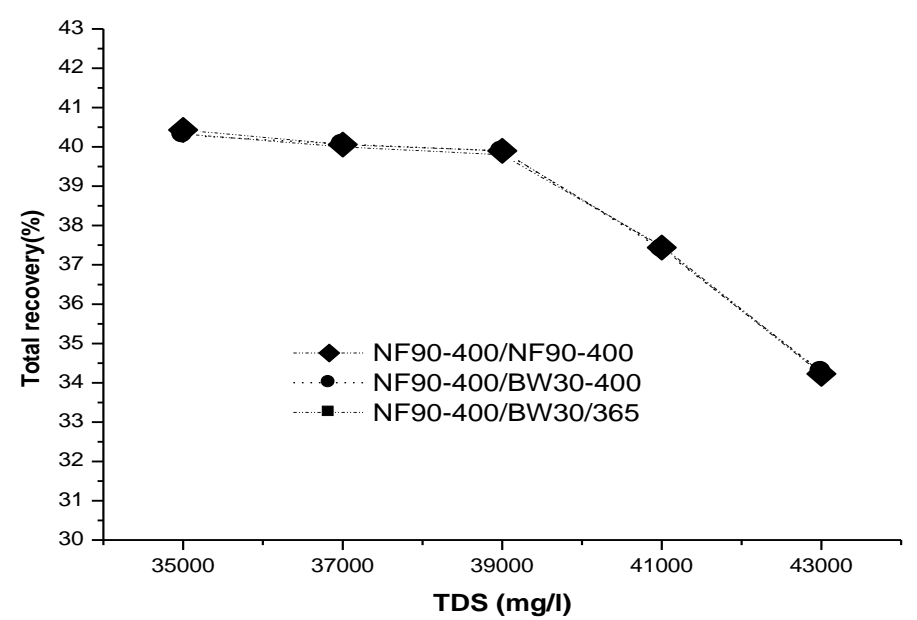

Figure 8: Variation of total recovery as a function of the initial feed salinity for the tested combinations.

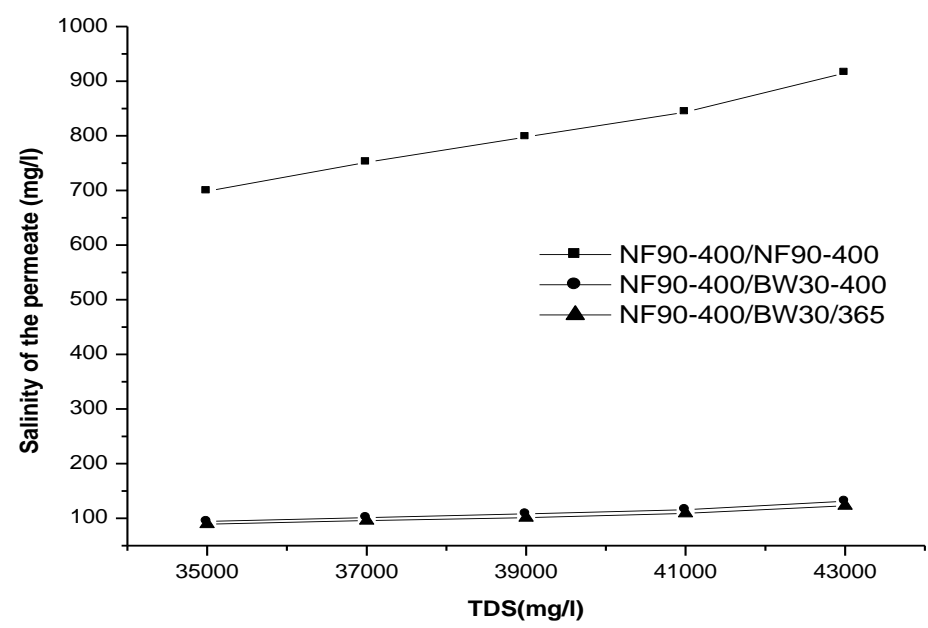

Figure 9: Variation of permeate TDS as a function of the initial feed salinity for the tested combinations.

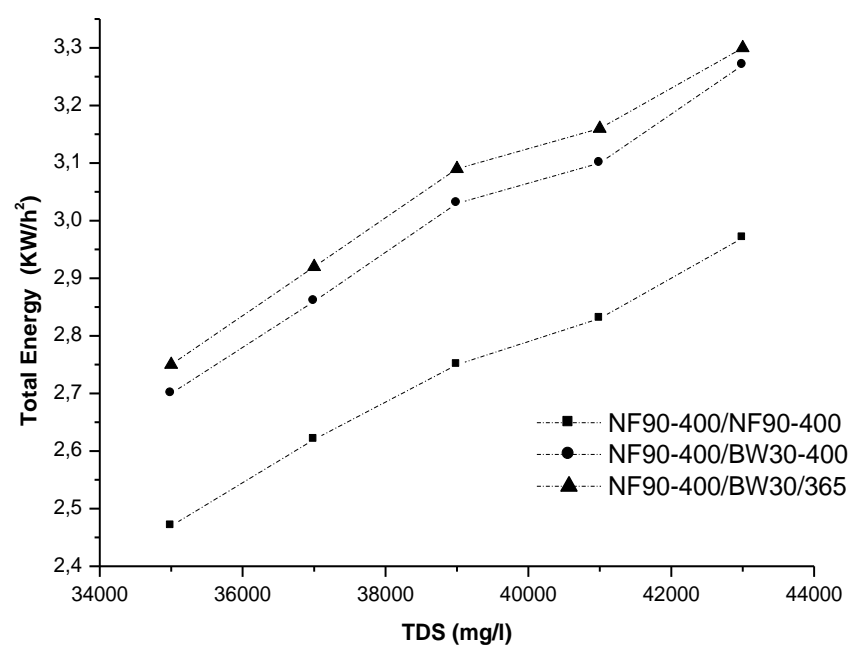

Figure 10: Variation of total energy consummation as a function of the initial feed salinity for the tested combinations 
According to the results mentioned above in dual stage in supplied Bach, the similar behavior and same phenomena of dual stage was observed in supplied bach, but the difference is manifested to the quality of product water, the values of total recovery and energy consummation. Table 4 gives the comparison the performance of tested configurations for each combination

Table 4: Comparison of two configurations tested for each combination.

\begin{tabular}{|c|c|c|c|c|c|c|c|}
\cline { 3 - 8 } \multicolumn{2}{c|}{} & \multicolumn{2}{c|}{ NF90-400/NF90-400 } & \multicolumn{2}{c|}{ NF90-400/BW30-400 } & \multicolumn{2}{c|}{ NF90-400/BW30-365 } \\
\hline Output parameters & $\mathrm{mg} / \mathrm{l}$ & $\mathrm{DS}$ & $\mathrm{DSSB}$ & $\mathrm{DS}$ & $\mathrm{DSSB}$ & $\mathrm{DS}$ & $\mathrm{DSSB}$ \\
\hline \multirow{3}{*}{\begin{tabular}{c} 
Total recovery $(\%)$ \\
\cline { 2 - 8 }
\end{tabular}} & 35000 & 18,87 & 49,33 & 18,87 & 49,33 & 18,87 & 49,33 \\
\cline { 2 - 8 } & 39000 & 12,24 & 40,45 & 12,24 & 40,45 & 12,24 & 40,45 \\
\hline \multirow{2}{*}{$\begin{array}{c}\text { TDS permeate } \\
(\mathrm{mg} / \mathrm{l})\end{array}$} & 43000 & 5,89 & 34,29 & 5,89 & 34,29 & 5,89 & 34,29 \\
\cline { 2 - 8 } & 35000 & 1151,9 & 698,72 & 161 & 94,28 & 150,54 & 89,37 \\
\cline { 2 - 8 } & 43000 & 2599 & 915,34 & 539,27 & 131,28 & 499,54 & 123 \\
\hline \multirow{3}{*}{\begin{tabular}{c} 
Energy $\left(\mathrm{Kw} / \mathrm{h}^{2}\right)$ \\
\cline { 2 - 8 }
\end{tabular}} & 35000 & 3,3 & 2,47 & 3,55 & 2,7 & 3,57 & 2,75 \\
\cline { 2 - 8 } & 43000 & 3,8 & 2,75 & 4,12 & 3,03 & 4,14 & 3,09 \\
\hline
\end{tabular}

DS: dual stage,

DSSB: dual stage supplied Bach.

A lower permeate TDS was achieved when BWRO membrane were used in stage 2 . The best quality of produced water is obtained with dual stage supplied Bach, all parameters respect the norms quality.

The comparison of the total recovery rate and energy consumption in RO and dual stage NF process at different feed salinity are plotted respectively in figure 11 and 12.

The analysis of the results shows that the total recovery rate of dual stage NF desalination process decreases sharply with the increase feed salinity. This is due essentially to the increase osmotic pressure, which reduces the supply pressure especially in the first stage. To maintain feed pressure within the design limits recommended by the manufacturing company, the recovery rate of first stage of NF has to be reduced with feed salinity and hence the overall recovery rate was reduced.

As to the RO process, the recovery rate was less affected by the feed salinity because the operating pressure in RO was almost twice that in NF membrane. However, the permeate TDS tended to increase with feed salinity for all applied pressures.

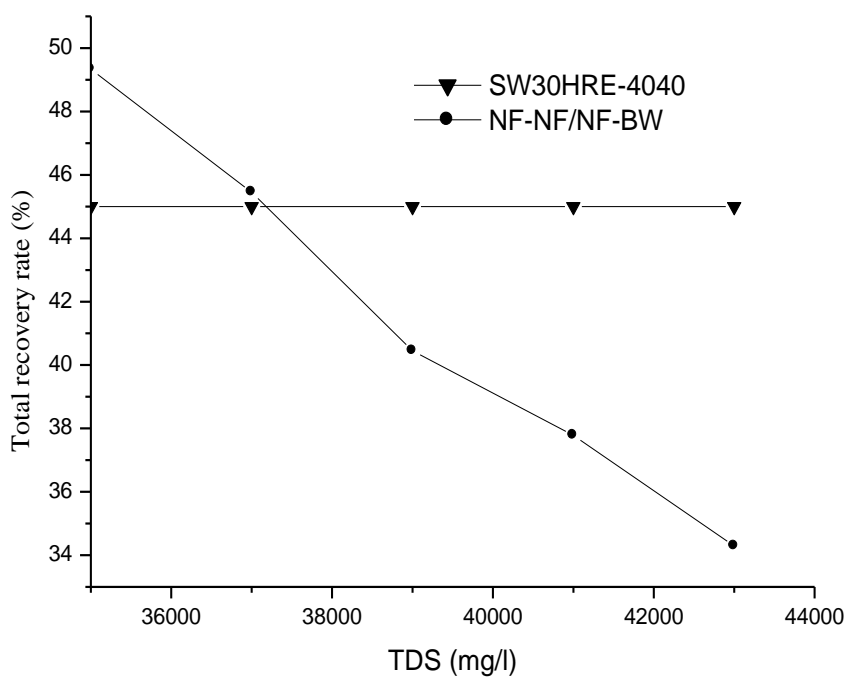

Figure 11: total recovery rate in RO and dual stage NF process at different feed salinity. 


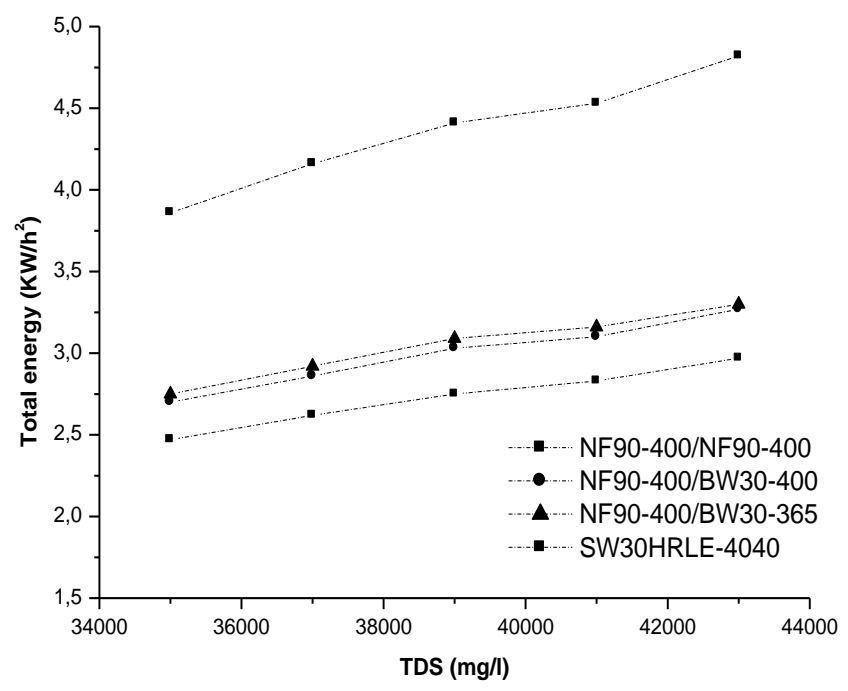

Figure 12: Energy consumption in RO and dual stage NF process at different feed salinity.

As expected, the energy consumption in dual stage NF-NF and NF-BW is lower than reverse osmosis in simple pass and the energy consumption in dual stage NF/BWRO was higher than in dual stage NF/NF membrane.

\section{Conclusion}

The results from the process simulation confirmed the feasibility of NF membrane in dual stage in seawater desalination. This study proposed another alternative in wich the NF membrane in second stage can be replaced by reverse osmosis membranes of low pressure (BWRO).

Using BWRO membrane in second stage reduced the system operating complicity and offered a better control of the permeate TDS over a wide range of feed salinity. Despite the high value of the energy consumed by BW membranes compared to that of NF, while the energy consumed by the system NF / BW is still below that consumed by reverse osmosis membrane.

Finally, the results of this study may be useful to conduct further investigations about the benefits of dual stage NF/BWRO desalination and its applicability in commercial desalination plants. It should be mentioned here that there will be some difference between the experimental and simulation results from ROSA. However, these results from ROSA are still reliable but a study in industrial scale is required to confirm them.

\section{References}

[1]. Chen. J., Li, G., (2005), Marine reverse osmosis desalination plant—a case study, Desalination 174 $299-303$.

[2]. Diem. X ., V.,(2006), Two stage nanofiltration seawater desalination system, United State Patent 7, 144, December 511 B2,

[3]. Karameldin. A., (2005), RO system design rehabilitation part I: sizzling feed intake management, 9th International Water Technology Conference, pp. 17-20, (Sharm El-Sheikh).

[4]. Moreno. F., Pinilla. A., (2004) Preliminary experimental study of a small reverse osmosis

[5]. wind-powered desalination plant, Desalination $171257-265$.

[6]. Nisan.S., Commercon. B., Dardour. S., (2005), A new method for the treatment of the reverse osmosis process with preheating of the feedwater, Desalination 182 483-495.

[7]. Noronha. M., Mavrov. V., Chmiel. Horst., (2002), Efficient design and optimisation of two-stage NF processes by simplified process simulation, Desalination 145 (1-3) 207-215.

[8]. Silva. V., Geraldes. V., Brites Alves. A.M., Palacio. L., Prádanos. P., Hernández. A.. (2011), Multi-ionic nanofiltration of highly concentrated salt mixtures in the seawater range. Desalination, Volume 277, Issues 1-3, 15, Pages 29-39.

[9]. Wang. X.L., Zhang. C.H., Zhao. J., (2000), Separation mechanism of nanofiltration membranes and its applications in food and pharmaceutical industries, Membrane Science and Technology 20 (1) 29-30. 